\title{
LA ESTÉTICA FIGURAL EN LA ÚLTIMA ESCRITURA Y TRABAJOS VISUALES DE ENRIQUE LIHN*
}

\author{
Juan Zapata Gacitúa** \\ Mariela Fuentes Leal ${ }^{* * *}$
}

\section{Resumen \\ En este artículo analizo la última producción creativa de Enrique Lihn; por una parte, la que está vinculada con su poesía y, por otra parte, la relacionada con sus trabajos visuales. Ambas variantes de su trabajo están en una estrecha relación hacia el final de su vida, lo cual es posible demostrar desde la estética figural de Jean-Francois Lyotard y sobre la base de la crítica que ha estudiado la etapa final de la vida y de la obra del creador chileno. \\ Palabras clave: Enrique Lihn, estética figural, comic, poesía chilena. \\ THE FIGURAL AESTHETIC IN THE LAST WRITING AND THE VISUAL WORK OF ENRIQUE LIHN}

\begin{abstract}
In this article I analyze the last creative production of Enrique Lihn. On one hand, the one related to his poetry, and on the other, the one related to his visual work. Both variations of his work have a close relation to the end of his life, a fact that is possible to demonstrate from the figural aesthetic of Jean-Francois Lyotard and on the basis of criticism that has studied the final stage of the life and the work on the Chilean creator.
\end{abstract}

Keywords: Enrique Lihn, figural aesthetic, comic, Chilean poetry.

Recibido: 04-08- 2014

Aceptado: 07-01-2015

\footnotetext{
Este artículo se inscribe en el Proyecto de Investigación Enrique Lihn en el siglo XXI: Desplazamientos teóricos, críticos y analíticos. Proyecto DIUC N²10.062.045-1.0, Dirección de Investigación de la Universidad de Concepción. La coinvestigadora, además, agradece el patrocinio en su investigación postdoctoral 2014-2016 al Council on Latin American and Iberian Studies en el Whitney and Betty MacMillan Center for Internacional and Areas Studies, en la Universidad de Yale; asimismo, agradece a la Comisión Nacional de Ciencia y Tecnología (CONICYT) y a la Universidad de Concepción.

** Chileno. Doctor de Philosophy de la Stony Brook University. Académico Universidad de Concepción, Concepción, Chile. juzapata@udec.cl

*** Chilena. Doctora en Literatura Latinoamericana de la Universidad de Concepción. Académica de la Universidad de Concepción, Concepción, Chile, e investigadora de la Universidad de Yale, Estados Unidos de Norteamérica. mariela.fuentesleal@yale.edu
} 


\section{Introducción}

En el contexto de un trabajo de actualización teórica, crítica y analítica de la obra de Enrique Lihn y, más específicamente, de la videósfera ${ }^{1}$, frente a la cual Enrique Lihn mantuvo una actitud activa y crítica, leo su última escritura en relación a sus trabajos visuales finales. Lo hago desde la estética figural de Jean-Francois Lyotard, desarrollada principalmente en su libro Discurso, Figura (1979). Utilizo la edición en Español, la cual cuenta con un estudio preliminar de Federico Jiménez Losantos, titulado "Prólogo a la edición castellana: A la deriva (para reparar en la obra de Jean-Francois Lyotard)" (9-42); es decir, recupero un pensamiento fundamental del filósofo francés, quien, como sabemos, ha sido objeto de estudio y polémica principalmente a partir de su reflexión sobre la postmodernidad en La condición postmoderna. Informe sobre el conocimiento (2004) y La posmodernidad (explicada a los niños) (2008). El rescate de la reflexión estética de Lyotard es posible, además, sobre la base del estudio que realiza sobre la totalidad de su obra Alberto Gualandi en Lyotard (2009). Aplico, de este modo, los conceptos específicos de esta mirada teórica en la última etapa de la creación literaria y visual de Lihn, relacionando, específicamente, La aparición de la Virgen $(1987,2012)$ con su Diario de muerte (1989) y con el comic Roma, La loba (1992, 2011), para evidenciar procedimientos y dimensiones de sentido comunes en sus últimos trabajos. Además, como telón de fondo, está el que se puede considerar su último trabajo crítico, la "Conversación inconclusa con Enrique Lihn (21 de junio de 1988)", con Rodrigo Cánovas, Roberto Merino, Lupe Santa Cruz y Miguel Vicuña Navarro; incluido en la revista Número quebrado 1. También, aquí se puede considerar el texto de Adriana Valdés "La escritura de Diario de muerte: un testimonio presencial", que forma parte de Enrique Lihn: vistas parciales (2008)2.

1 Régis Debray en su Vida y muerte de la imagen. Historia de la mirada en Occidente (1994), distingue, en síntesis, tres eras de la comunicación: “A la logósfera correspondería la era de los ídolos en sentido amplio (del griego eidolon, imagen). Se extiende desde la invención de la escritura hasta la de la imprenta. A la grafósfera, la era del arte. Su época se extiende desde la imprenta hasta la televisión en color (más pertinente, como veremos, que la foto o el cine). A la videósfera, la era de lo visual (según el término propuesto por Serge Daney). Ya estamos" (176). También, en El arcaísmo posmoderno. Lo religioso en la aldea global (1996), sintetiza: "Para hablar en términos de mediología, está claro que la videosfera actual, o tercera era de la comunicación luego de la logosfera -era de la escritura- y la grafosfera -era del impreso-, tiene muchas de las características del primer periodo, como logosfera" (52).

2 En un registro más lúdico está, además, el libro de Mario Valdovinos Lihn La muerte (2012), definido por su autor como "una autobiografía conjetural de Enrique Lihn" (78 y 167). En este trabajo experimental, Valdovinos, mediante una escritura informada y subjetiva, integra información referencial y textos de Lihn, algunos reconocibles, otros evidenciados en notas, para dialogar con un interlocutor ausente que habla desde la muerte. En cuanto la crítica que se ha ocupado de la última escritura poética de Lihn y de las circunstancias que la rodearon, remitimos, por ejemplo, a: CorreaDíaz (1996), Lastra/ Valdés (1989), Rodríguez (1993), Sarmiento (2001), Travis (2007), Zapata Gacitúa $(1988,1991,1994)$. 


\section{La estética figural de Lyotard}

Por una parte, el Prólogo de Jiménez Losantos a Discurso, Figura, permite conocer una visión de Lyotard cuando no era todavía el pensador famoso de la postmodernidad y, sobre todo, era conocido como uno de los jóvenes teóricos post mayo del 68, en el paradigma de los filósofos deseantes, junto a Deleuze/Guattari, y con un trabajo que guardaba relación con la Kristeva de esos años, la de La revolución del lenguaje poético (1974). Por otra parte, el libro de Gualandi informa de la evolución de su reflexión desde la fenomenología y el marxismo hasta el nihilismo apocalíptico de sus últimos años. Así, Alberto Gualandi en el capítulo II de su estudio "El afuera del lenguaje" (pp. 43-63), apartado "Más allá del "sentido" y de la "referencia", sitúa el libro, el origen y objetivo de Discurso, Figura:

En las primeras páginas de su tesis de doctorado, su primera obra de gran envergadura, Discurso, Figura (1971), Lyotard parece asignar a su reflexión un objetivo difícil y arriesgado, que consiste en emplear los conceptos y el lenguaje del discurso teórico - de las ciencias humanas y de la filosofía- para mostrar lo que hace la verdad del arte irreductible a toda teoría, para decir esto que para todo discurso teórico parece imposible decir, y que él llama aquí figura. $(43)^{3}$

La figura o lo figural se manifiesta, agrega Gualandi en su lectura de Lyotard, cuando lo no dicho se muestra en el discurso, con la fuerza de un acontecimiento que lo fractura y donde se materializa el arte. Y en el trabajo onírico se presenta con una gradual intensidad. Primero, a través de una figura imagen: "Es, por lo tanto, a partir de estas deformaciones que el trabajo onírico se revela para Lyotard como figura imagen que confunde los contornos bien delimitados que definen los elementos discursivos y perceptivos de lo real . El cuadro de Picasso donde una silueta de mujer se compone de varios perfiles y posturas diferentes ofrece, según Lyotard, un buen ejemplo de lo que es una figura imagen" (50). Segundo, lo anterior se intensifica a través de una figura forma, en la que en un plano de pura inmanencia funcionan "procesos deseantes primarios", "líneas de fuerza" intensivas que no refieren a la unidad de

3 Las traducciones del estudio de Gualandi son mías. 
ningún objeto: “La pura circulación energética de líneas y colores de un cuadro de Pollock es, dice Lyotard, una revelación pictórica ejemplar de esta figura forma que anima profundamente lo visible ordinario sin poder por tanto ser jamás vista" (50). Tercero, existe un tercer estrato más profundo, la figura matriz o matriz fantasmática, en la lectura de Gualandi, "es la que no puede ser ni leída ni vista, la que surge de una topología fantasmática que atraviesa todos los espacios: discursivos, perceptivos, oníricos, figurales, sin mostrarse jamás" (51), la cual está relacionada con la pulsión de muerte freudiana.

\section{Una escritura personal previa}

Como una forma de crítica a la videósfera y a uno de sus efectos, la desaparición de la memoria, surge una tendencia en la crítica literaria subjetiva y autorreferencial, en la realidad de un campo cultural literario en crisis. Así, suscribo esta opción y explícito mi propia experiencia como investigador sobre, prácticamente, toda la producción literaria de Lihn, desde 1984 hasta hoy día; asimismo, recupero fragmentos de mis conversaciones con el poeta desde 1985 hasta 1988, poco antes de su muerte; es decir, precisamente, en los años en que produjo la obra escritural y visual objeto de este trabajo. De esta manera, escribo y recuerdo las últimas conversaciones con él, las que estuvieron relacionadas con mi viaje y estadía durante cinco años, a fines de los años ochenta e inicios de los noventa del siglo pasado, como estudiante de doctorado, en la Universidad del Estado de Nueva York en Stony Brook, Long Island, a una hora, más o menos, de Manhattan. Mi viaje y estadía en ese lugar, por lo demás, estuvieron patrocinados por Lihn y producto de su amistad con Pedro Lastra, profesor en esos años de esa universidad.

A fines de agosto de 1987, tomé el avión hacia Nueva York y el último trámite que realicé en Santiago fue visitarlo en su departamento de la calle Passy, en el límite de Providencia y Nuñoa, y donde, en varias ocasiones, habíamos conversado, pues me había ofrecido quedarme en su casa cada vez que fuera a Santiago desde Concepción. Ese día era una tarde de sol y me dijo que en Stony Brook estaban esperando a otro chileno y que el lugar me iba a gustar; también, me sugirió que me hiciera de amigos lo antes posible, que no lo dejara para después. Ahora recuerdo que, en el primer invierno de allá, enero o febrero de 1988, desde una casa rodeada de nieve, en Port Jefferson, le escribí contándole mis primeras impresiones de lo que, hasta ese momento, había conocido de Estados Unidos y de la 
Universidad de Stony Brook; principalmente de su biblioteca, en la que, finalmente, había podido leer su novela Batman en Chile (1973). Además, le pedía que me enviara un ejemplar de La aparición de la Virgen, que recién había publicado, lo cual hizo a través de Pedro Lastra; pero que, por extrañas circunstancias, nunca llegó a mis manos. En esos mismos meses, Pedro Lastra me dijo que Lihn estaba teniendo algunos problemas de salud. Llegó la primavera a Long Island y, con ella, la posibilidad de volver por algunas semanas a Concepción. Al llegar a Santiago, lo primero que hice fue llamarlo y preguntarle por su salud. Me dijo que la situación era complicada y que, en ese preciso momento, estaba siendo acompañado y trasladado por unos amigos a Viña del Mar; pero, agregó que si yo iba a Santiago, lo llamara para reunirnos a conversar. Así, en el mes de junio de ese año, lo visité en su departamento de la calle Passy; sin embargo, ahora, algo había cambiado: un aviso junto al citófono del edificio, dirigido a sus amigos, les informaba de su estado de salud. De todas maneras, toqué el timbre y él se asomó en una ventana del tercer piso y me lanzó unas llaves para que entrara. En realidad, yo esperaba encontrarme con una persona moribunda en una cama; pero era el mismo Lihn de siempre: amable, digno, de negro y de pie. Como lo consigna en su último diario, ahora la casa estaba ordenada y una mujer sirvió el almuerzo: comida china. Conversamos de cualquier cosa, menos de su enfermedad, y tuve que pedirle otro ejemplar de La aparición de la Virgen; le pide que me escribiera algo, como siempre lo hacía con los libros que me daba. Este ejemplar, posteriormente, también desapareció en Stony Brook y de él sólo recuerdo la dedicatoria: "Para Juan Zapata y que todo siga bien". Nos despedimos sin dramatismo ${ }^{4}$. De regreso en Stony Brook, yo ya no vivía en la casa de Port Jefferson, sino en Stony Brook Village. Allí, una mañana, recibí una llamada telefónica de Jaime Giordano, profesor chileno de Stony Brook en ese tiempo, para que fuera a su departamento en Manhattan. Me trasladé hasta allá y durante una mañana estuvimos recorriendo la ciudad, visitando museos y galerías de arte; así, en una exposición de trabajos plásticos desconstructivistas, me dijo que Enrique Lihn había muerto. Después, en la Navidad de 1988, Pedro Lastra me regaló una copia de los textos transcritos por él y Adriana Valdés, todavía sin editar, de Diario de muerte. Este relato de

4 Este relato se confirma en dos cartas incluidas en el libro Querido Pedro: Cartas de Enrique Lihn a Pedro Lastra (1967-1988) (2012); específicamente en las cartas con fecha 13 de abril de 1988 (97-98) y [s/d, 1988] (99). 
desapariciones, sobre todo de uno de los libros que pongo en relación hoy día, se actualizó de manera extraña en el verano del año 2012, pues, a propósito de la búsqueda de otro libro inencontrable, la primera edición de La nueva novela (1977) de Juan Luis Martínez, Pedro Lastra me hizo llegar dos ejemplares de la primera edición de La aparición de la Virgen que todavía estaban por ahí.

\section{La crítica: textos propios y trabajos recientes}

Respecto a trabajos críticos que se ocupan de los trabajos de Lihn que ahora comento dejo constancia de dos reseñas escritas por mí en el momento de la publicación de La aparición de la Virgen y de Diario de muerte. En primer lugar, constato que exactamente una semana antes del fallecimiento del poeta, el 10 de julio de 1988, apareció una reseña mía en el diario El Sur de Concepción. De ella, sintetizo y cito algunas ideas que todavía están vigentes y las contextualizo en el pensamiento teórico de Lyotard.

En La aparición de la Virgen, el tema central de la publicación era un hecho político, religioso y mediático: las supuestas apariciones de la Virgen del Carmen, patrona de Chile, en Villa Alemana. En el texto, el proceso de "aparición" se produce gradualmente, en forma gráfica y escrita ${ }^{5}$. La aparición gráfica se produce fragmentariamente al inicio y siguiendo las técnicas de los acercamientos y detalles del cine y la fotografía; desde la página 2 a la 6 aparecen la cara de la Virgen, la bandera nacional, remolinos de papel, volantines; en la página 7 , una imagen amplia recoge todos estos elementos dispersos: una virgen muy terrenal junto a un ángel grotesco es fotografiado por un fotógrafo antiguo. En la página 9, termina el poema reiterándose el proceso de manipulación de los símbolos y las imágenes nuevamente se fragmentan. Además, coherente con la función desacralizadota de las imágenes y el texto del poema, su lenguaje parodia al discurso religioso.

Así, creo que la segunda edición de La aparición de la Virgen, incluido en La aparición de la Virgen y otros poemas politicos (1963-1987) (2012), no obstante el entusiasmo y la diligencia de Andrés Florit C., a cargo de la selección y edición, tergiversa el espíritu, la letra y la visión de Enrique

5 Para la mejor comprensión del lector o receptor de este trabajo, en Anexo incluyo los dibujos y páginas a las cuales aludo. 
Lihn; es decir, la publicación sin imágenes del texto es otro texto, otra virgen. La primera edición, más bien, por su formato de periódico, para ser vendido en los kioscos como El Paseo Ahumada (1983), como quería Lihn, de la misma manera que el cómic Roma, La Loba, mostraban el interés permanente de Lihn por alejarse y alejar a la literatura del Poder: editorial, económico, crítico, académico. Esto, desde la definición de cómic que da Alejandro Jodorowsky en el diálogo que antecede a Roma, La Loba, "Hablando de comics con Alejandro Jodorowsky" (7-25), ausente, también, en la segunda edición de este trabajo de Lihn. Allí, Jodorowsky define esa forma marginal de expresión artística:

El cómic para mí es un arte maravilloso, pero hay que tomarlo como un arte industrial. Es totalmente diferente de las vanidades de la literatura. Cuando hablas con un poeta o con un novelista, se toman como la gran cosa. Son usados políticamente, son honoríficos, tienen premios establecidos, etc. El cómic es humilde, no es considerado arte, es despreciado. Hay que partir de la base de que es un arte, pero un arte industrial, que es un oficio más. Es lo primero que hay que visualizar. (8)

Por su forma, el trabajo escrito y visual de Lihn, se contextualizaba en un paradigma de poetas y artistas visuales muy reconocidos de ese tiempo. Por ejemplo, la integración de imagen visual y texto lingüístico lo relaciona con Juan Luis Martínez; su lenguaje violento y desmitificador lo acerca a Diego Maquieira; la actualización de imágenes arquetípicas de la cultura popular chilena se asemeja a la obra de Eugenio Dittborn. Lo anterior, frente a una realidad sobredimensionada negativamente, desde el inicio del texto:

La realidad es el único libro que nos hace sufrir

La realidad es la única película que nos quita el sueño

Las apariciones de la Virgen serán irreales no así la aparición

de los agentes de la realidad. (2)

El trabajo de Adriana Valdés, antes mencionado, constituye una mirada clínica sobre la evolución de la enfermedad terminal de Lihn y con el objetivo de aclarar detalles respecto a aspectos cotidianos que han quedado en una nebulosa. Así, de acuerdo a información que ella desclasifica, el proceso de creación y de edición de La aparición de la 
Virgen, se habría producido cuando ya Lihn sabía de su verdadero estado de salud y, por lo tanto, condicionado por la enfermedad. Sin embargo, como dimensión fundamental de él, y más allá de la enfermedad o junto con ella y la contingencia política chilena de los años setenta y ochenta, está la estética figural de Lyotard en todas sus variantes.

$\mathrm{Al}$ respecto, me apoyo en el importante trabajo de Alvaro Bisama, "El temblor en el trazo" (5-8), que introduce la segunda edición de Roma, la loba. El sentido y detalles técnicos de los dos trabajos que comento quedan muy claros en la mirada de Bisama, quien, en primer lugar, constata cómo en un congreso de literatura, en el verano del año 1992, se había detectado la necesidad de estudiar Diario de muerte en relación a Roma, la loba, a lo cual nosotros agregamos La aparición de la Virgen. En seguida, explicita el sentido de la última etapa de producción artística y literaria de Lihn:

De este modo, habría que leer al Lihn terminal como el avance de una política de los signos en descomposición de la historia de la república chilena. La fecha de su muerte no es menor. Lihn muere a la vuelta de la esquina de nuestro pasado reciente y no alcanza a verlo. Antes ha decidido volcarse hacia la anotación crítica de su propio presente (...). En cierto modo, el arte del último Lihn es el arte de la predicción de las formas, un arte del apuro, de la falta de cálculo, de la ausencia de escrúpulos. Es como si en la década del ochenta, Lihn cancelara todo futuro y se empeñara en quemarse casi de modo instantáneo, explotando en pedazos, actuando de modo viral, lanzándose al video arte, al cómic, a la crítica, al ensayo de arte sin pensar en los límites que separan cada uno de sus proyectos que terminaban mezclándose, convirtiendo todo en una suerte de diario múltiple que se escribe a través de cortes e interrupciones, de inmersiones en formas tan frágiles que eran muchas veces ejercicios de estilo tan irrepetibles como demoledores. (6)

Sin explicitarlo, veo funcionando en esta descripción de Bisama, las variantes de la estética figural; es decir, la figura imagen, la figura forma y la figura matriz, en términos de una composición/descomposición, escritural y visual, que muestra la desaparición de un proyecto individual y colectivo, tal como aparece sugerido en el dibujo de la página número 
4 de La aparición de la Virgen y a lo largo de todo el cómic. Lo anterior, se reafirma si recuperamos una síntesis de Lyotard en Discurso, Figura respecto a los componentes de lo figural:

La figura imagen, la que veo en la alucinación y en el sueño, que viene dada por el cuadro, la película, es un objeto colocado a distancia, tema; pertenece al orden de lo visible: trazado revelador. La figuraforma está presente en lo visible,visible ella misma en rigor aunque en general no vista: es el trazado regulador de André Lhote; la Gestalt de una configuración, la arquitectura de un cuadro, la escenografía de una representación, el encuadre de una fotografía, en suma el esquema. La figura-matriz es invisible por principio, objeto de represión orginaria, mezcla inmediata de discurso, fantasma "originario". Sin embargo, es figura, no estructura, porque de entrada es violación del orden discursivo, violencia hecha a las transformaciones autorizadas por este orden. (274)

Lo anterior, se confirma cuando Bisama se refiere a los detalles técnicos en la composición del cómic, válidos también para los dibujos de La aparición de la Virgen:

Lihn es quizás un dibujante realista que lucha contra esa facilidad boicoteándose una y otra vez: llama la atención el detalle técnico que le otorga a los vehículos y los ambientes al lado de cómo despacha la silueta humana, casi siempre al borde de la desfiguración. Por otra parte, en los globos de texto las palabras casi no caben, como si lo que dijeran los personajes -en vez de complementar la imagen o proponer un contrapuntofuera tan solo un murmullo cuyo sentido final es justamente evidenciar esa confusión. Esa confusión aparece también en el trazo, que casi nunca usa pinceles gracias a un achurado extensivo que sacrifica cualquier clase de profundidad de campo en aras de la composición de la página. (7)

Además del texto principal que da título a la publicación, los poemas restantes tematizan situaciones límites bien específicas del acontecer nacional de los años ochenta en Chile: jurídicas, "No hay derecho" y "Limitaciones legales; político-policiales, "Chiu-Chiu" y "Tú eres nuestro hombre". El poema "Saldos del Paseo Ahumada" vuelve sobre el problema del comercio ambulante y de la violencia en esa calle de Santiago. También, aquí aparece de manera irónica la disfuncionalidad de la práctica escritural, lejos del tono de autoafirmación de la poesía 
presente en el más citado poema de Lihn, "Porque escribí", parodiado años antes por Rodrigo Lira en el texto "ARS POETIQUE, DEUX" (31), de su Proyecto de Obras Completas (1984), y, después, por Roberto Bolaño en un pasaje de Los detectives salvajes (2007), en la voz de Auxilio Lacouture (198), y aquí por el mismo Lihn, a tono con el desencanto e ironía de los años ochenta:

Escribo para desquitarme de la inacción que significa escribir

Escribo como alguien compra un número de la lotería atrasado

Escribo de parte de los perdedores para la mortalidad

Escribo sin voz por amor a la Letra

Escribo, luego el otro existe. (14)

El último poema incluido, "El castillo", describe la situación de los jóvenes de ese tiempo, tematiza a la juventud víctima de un tiempo negativo que trasciende las fronteras nacionales y que, por lo mismo, hace coherente sus modas y sus gestos con los jóvenes de cualquier ciudad del mundo, perdida la conciencia de progreso y de futuro.

Respecto a mi trabajo anterior sobre Diario de muerte, una reseña publicada en la Revista de crítica literaria latinoamericana 33, en el primer semestre de 1991, y con mil erratas, rescato el último fragmento:

Finalmente, la trascendencia de Diario de muerte responde a su inscripción en una forma de literatura definida por Julia Kristeva en el capítulo "Poesía y negatividad", del libro Investigaciones para una semanálisis (París: Du Seuil, 1969) como un espacio de "escritura paragramática", una escritura ambigüa, en el límite del sentido, que exige una lectura doble o más de una lectura y en la cual el sujeto se eclipsa: su desaparición implica la del lenguaje, la de la escritura, y el advenimiento de los "fenómenos secundarios" o "marginales": el sueño, la poesía, la locura -algunos de los temas de Diario de muerte, escritos por "un sujeto zerológico", equidistante de todo, un no-sujeto que asume a un pensamiento que se anula. (327)

En otras palabras, la teoría de Kristeva es la expresión más hacia la escritura de la estética figural de Lyotard, inclinada a lo visual, las cuales confluyen en la última escritura poética y en los trabajos visuales finales de Enrique Lihn. 
La presencia de la estética figural como figura matriz y pulsión de muerte es obvia en el último diario de Lihn, es el tema; por lo tanto, sólo llamo la atención, hacia el final, de "intertextualidades" específicas entre Diario de muerte y Roma, la loba. Observo esto en los poemas "Muerte en la ópera" (32-33), y "El Espejo de la Señora" (69), que reenvían a las páginas finales de Roma, la loba; páginas 79-81, en la primera edición; páginas 61-63 (remito al Anexo), en la segunda edición. Idea que me parece clara con la lectura de "El Espejo de la Señora":

La vida se despide de sí misma, cifrándose

en esperanzadas fantasmagorías

que duran lo que dura el trance de la muerte. Mejor barrerlo todo

tener la cabeza limpia como un espejo que la Señora coja para mirarse en él y rompa con su aliento todopoderoso.

Así, surge una ecuación: Señora = Muerte. (69)

Esto, de algún modo, remite a una de las fotografías que acompañan a la "Conversación inconclusa" con Cánovas y otros en el $\mathrm{N}^{\circ} 1$ de la revista Número quebrado (4), donde aparece Lihn disfrazado de la muerte.

De esta manera, como CONCLUSION, una ecuación final: Vida = Espejo $=$ Irrealidad $=$ Muerte. 
ANEXO 1: Páginas y dibujos de La aparición de la Virgen (Siguiendo la primera edición del texto, conservamos el lugar de la imagen en el contexto de la página)

Página 2:
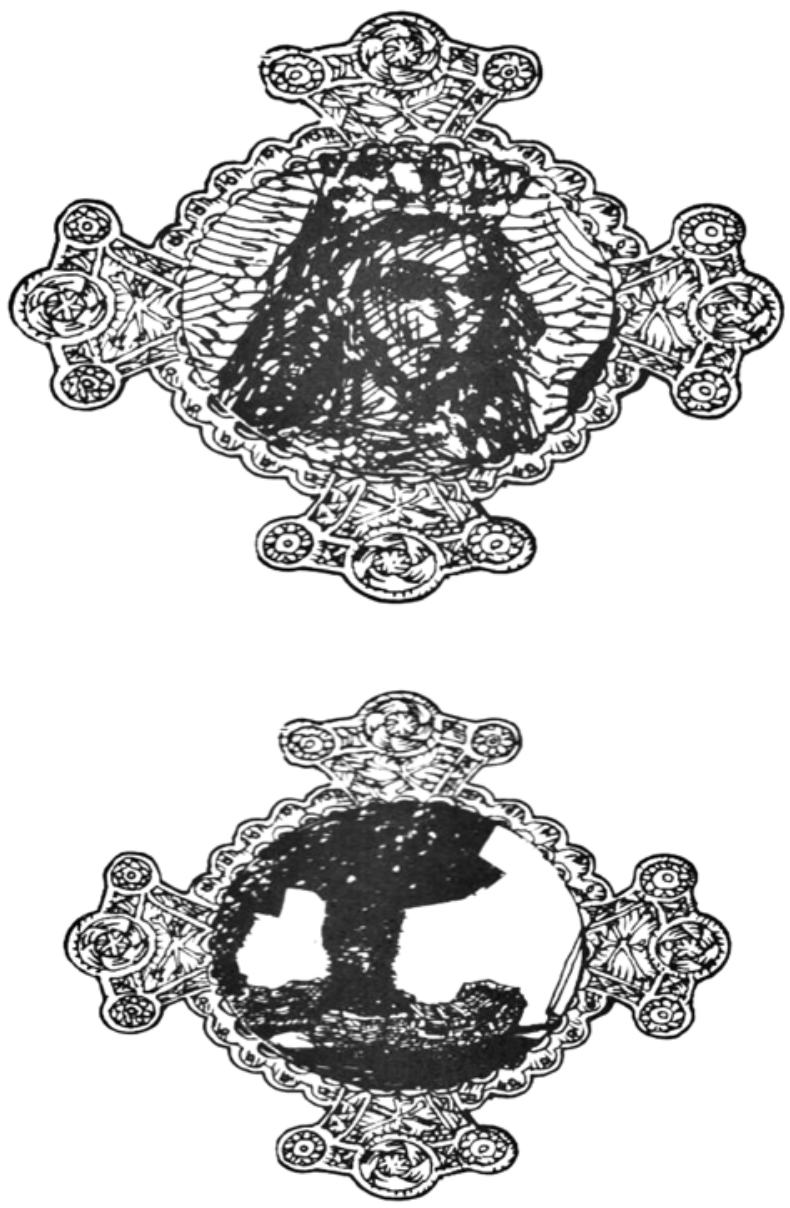
Página 3:

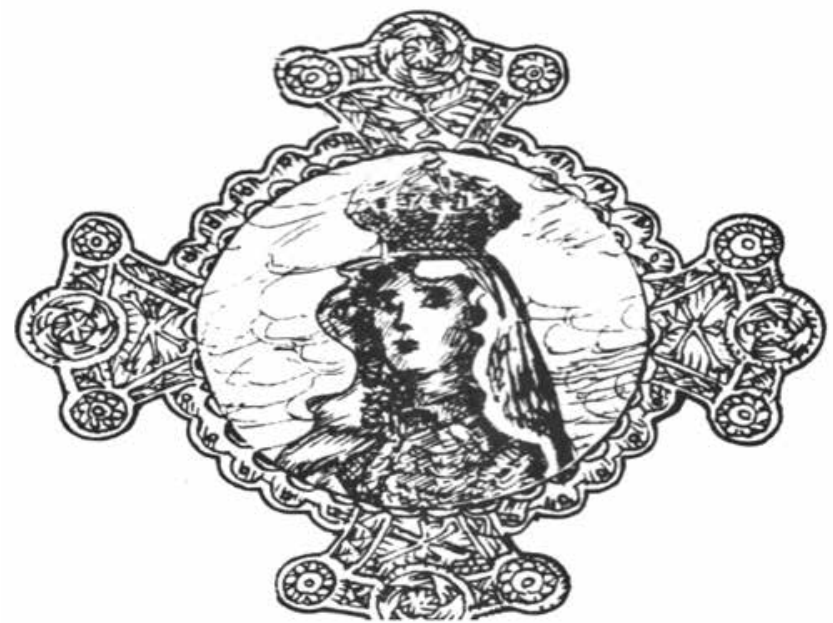

Página 4:

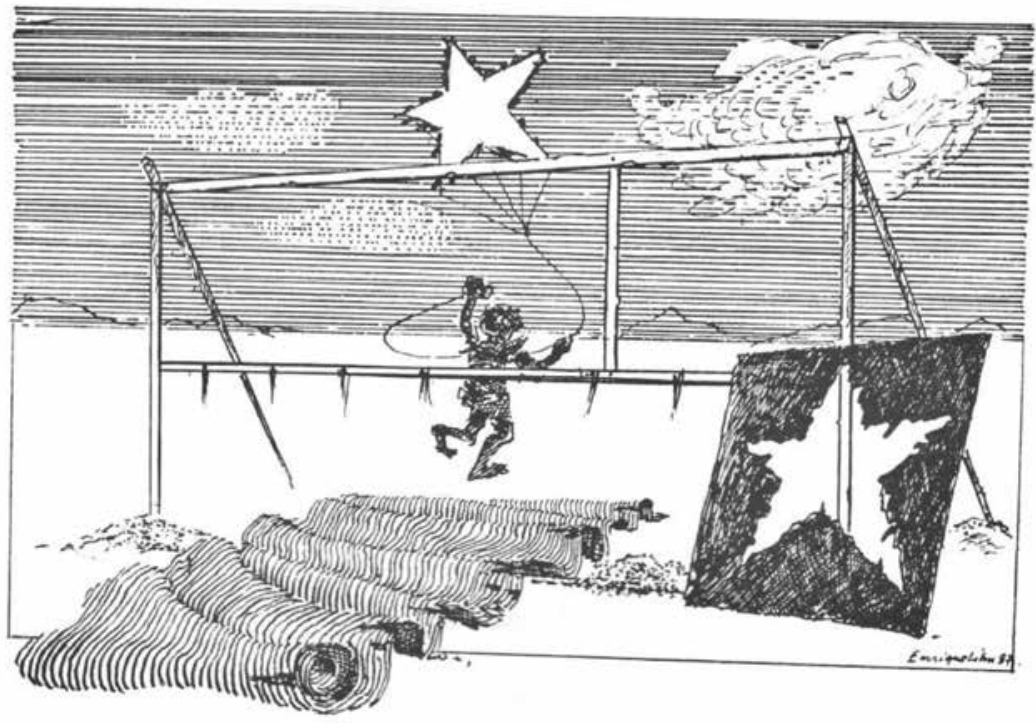


Página 5:
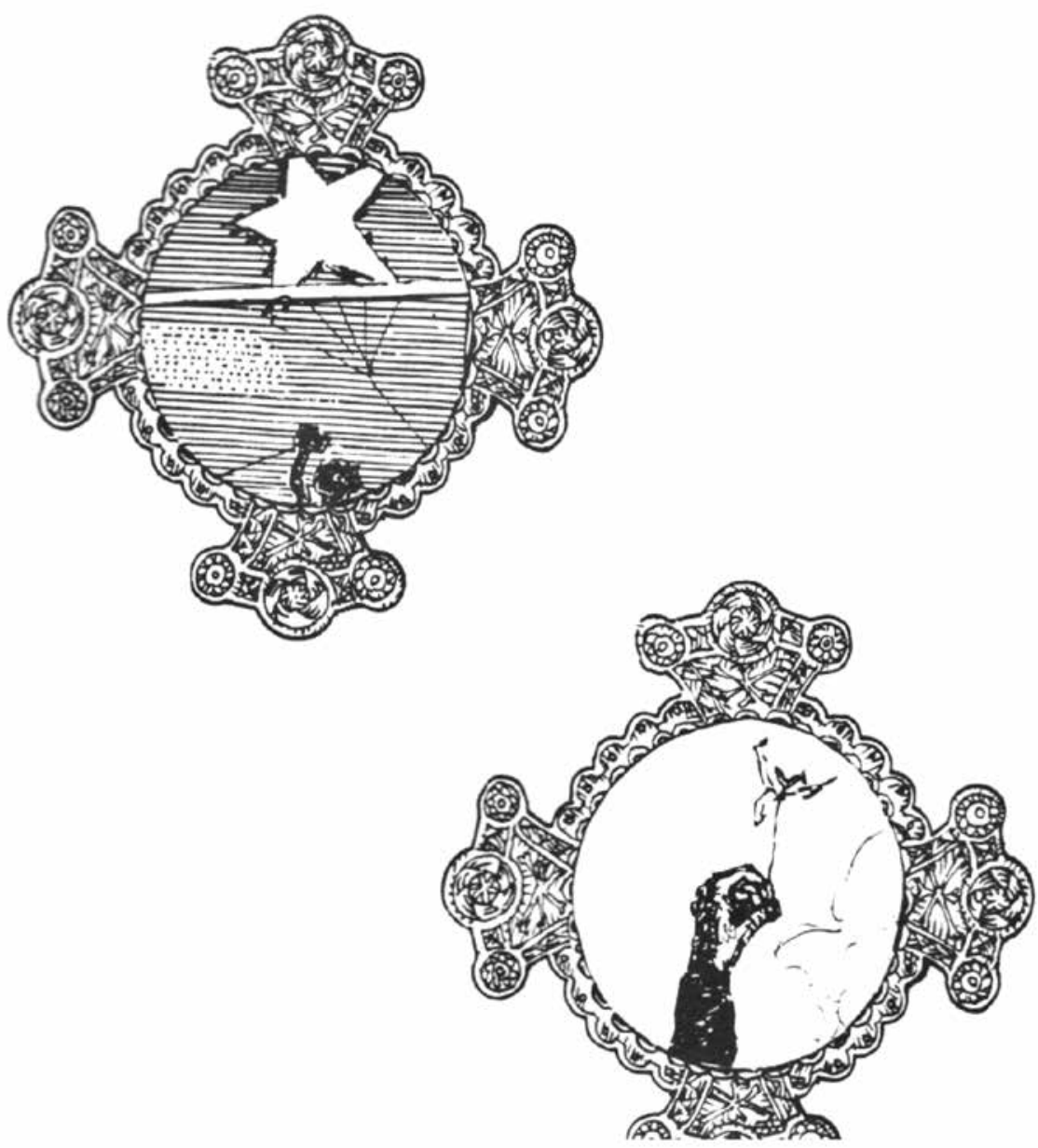
Página 6:

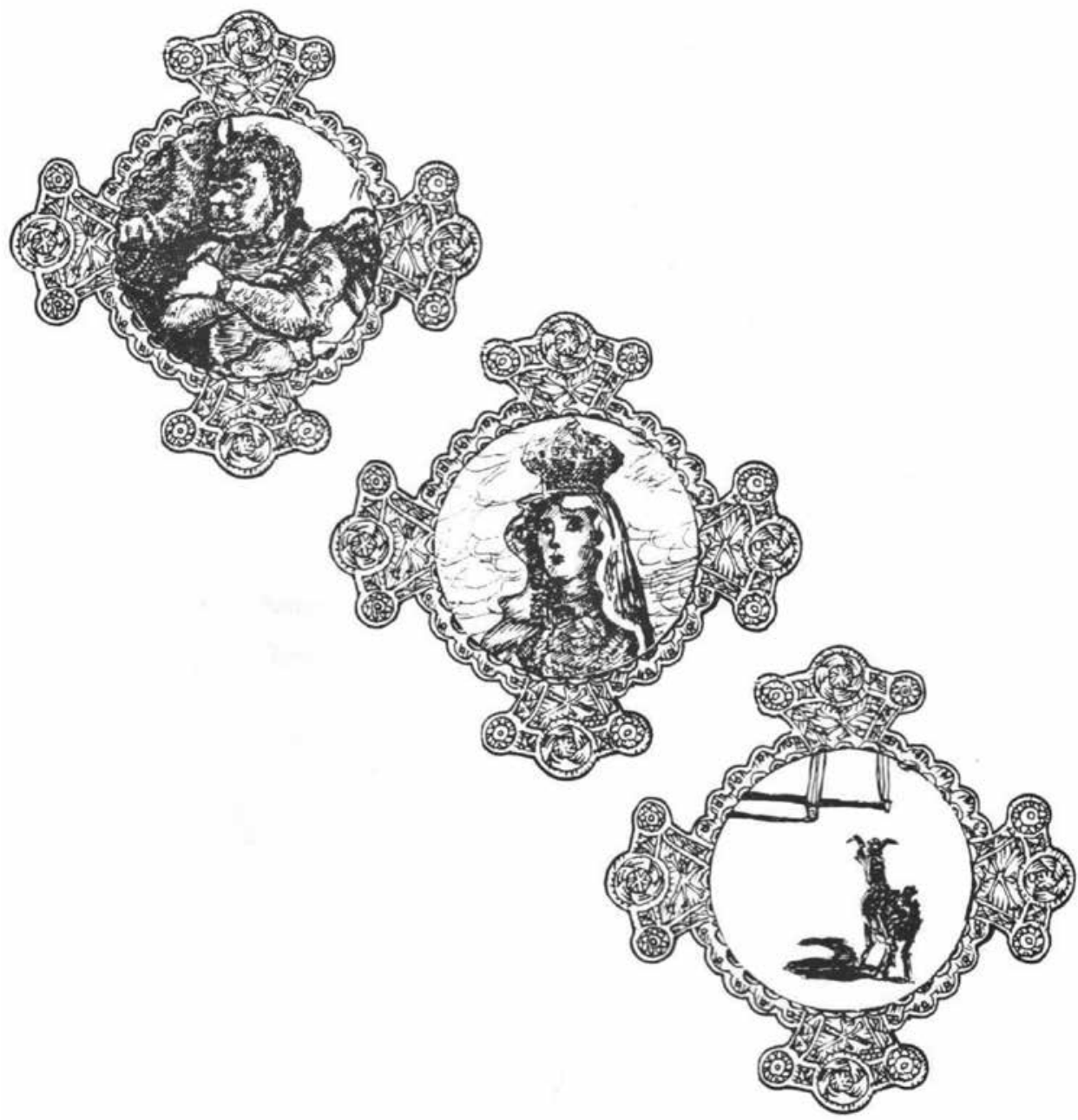


Página 7:

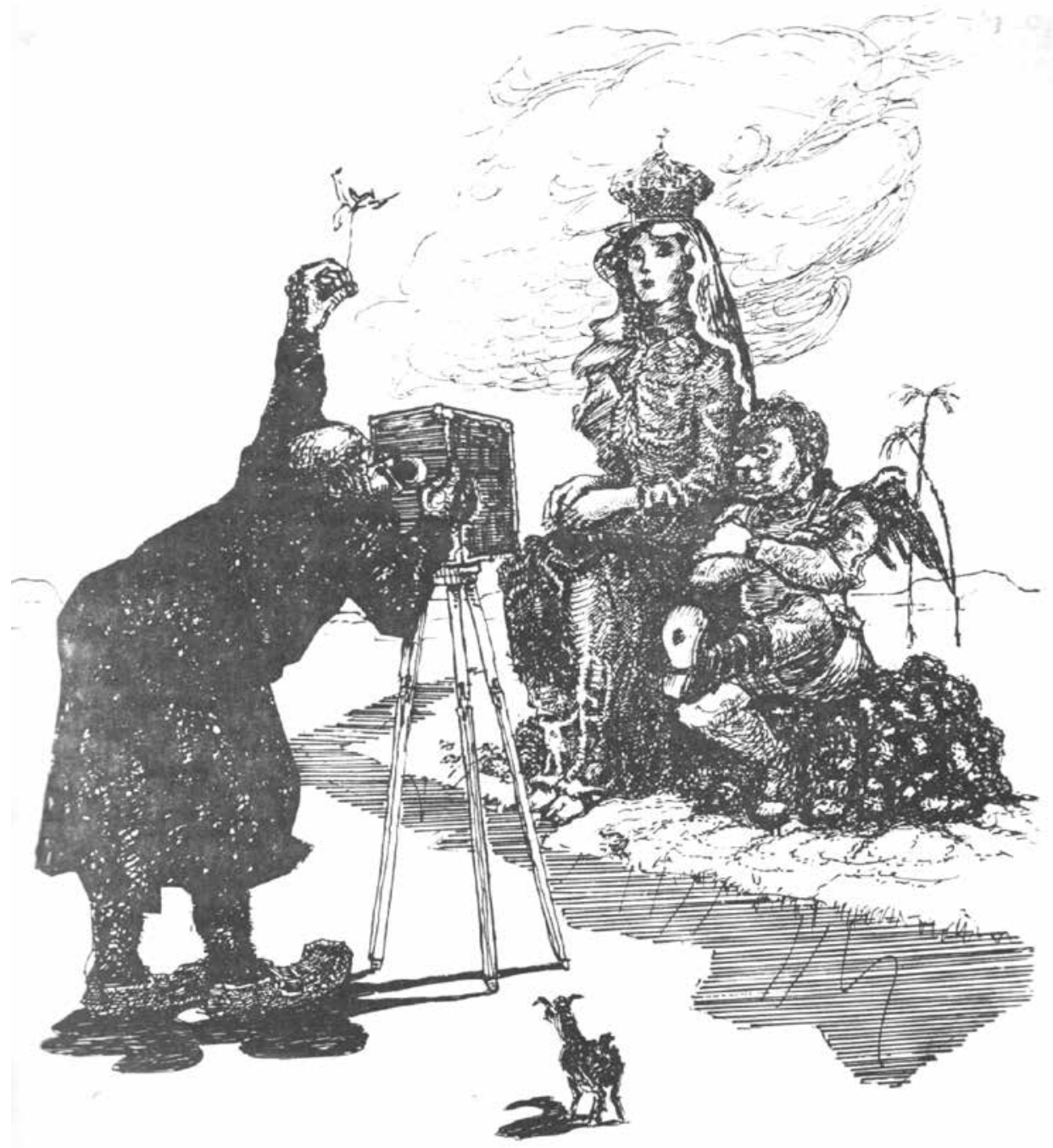


Página 8:

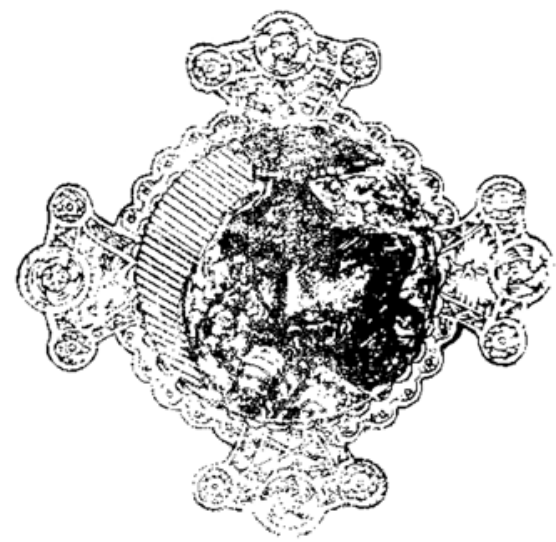

Página 9:

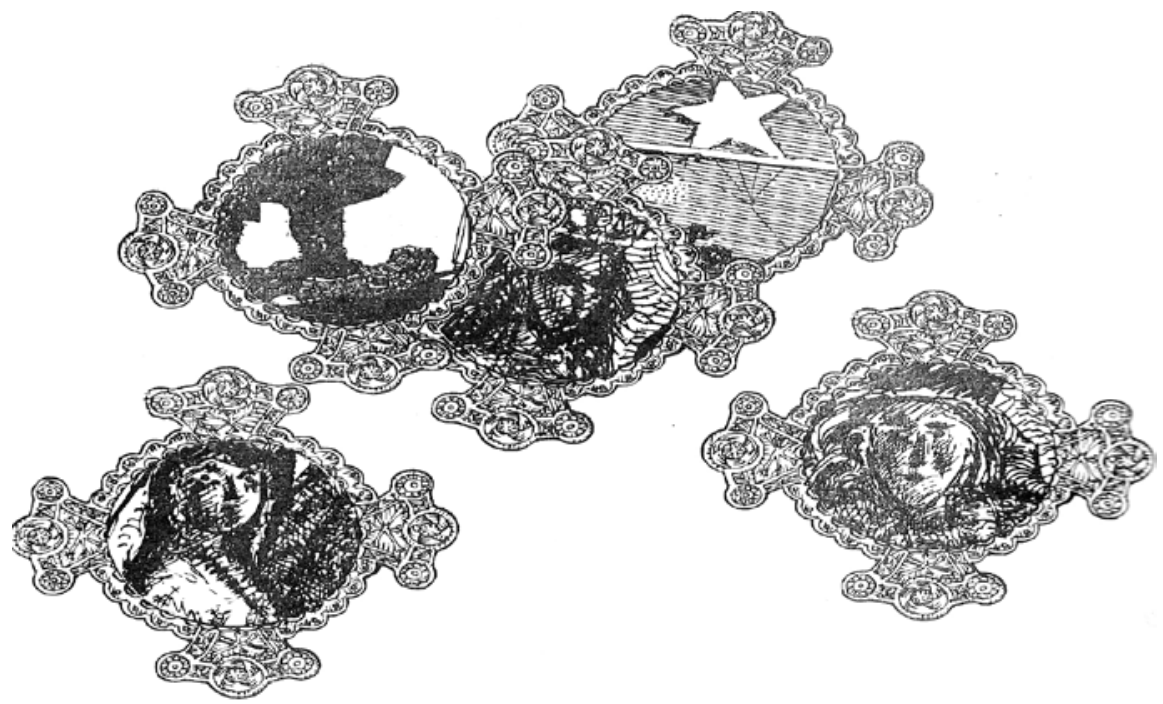


ANEXO 2: Imágenes de Roma La Loba
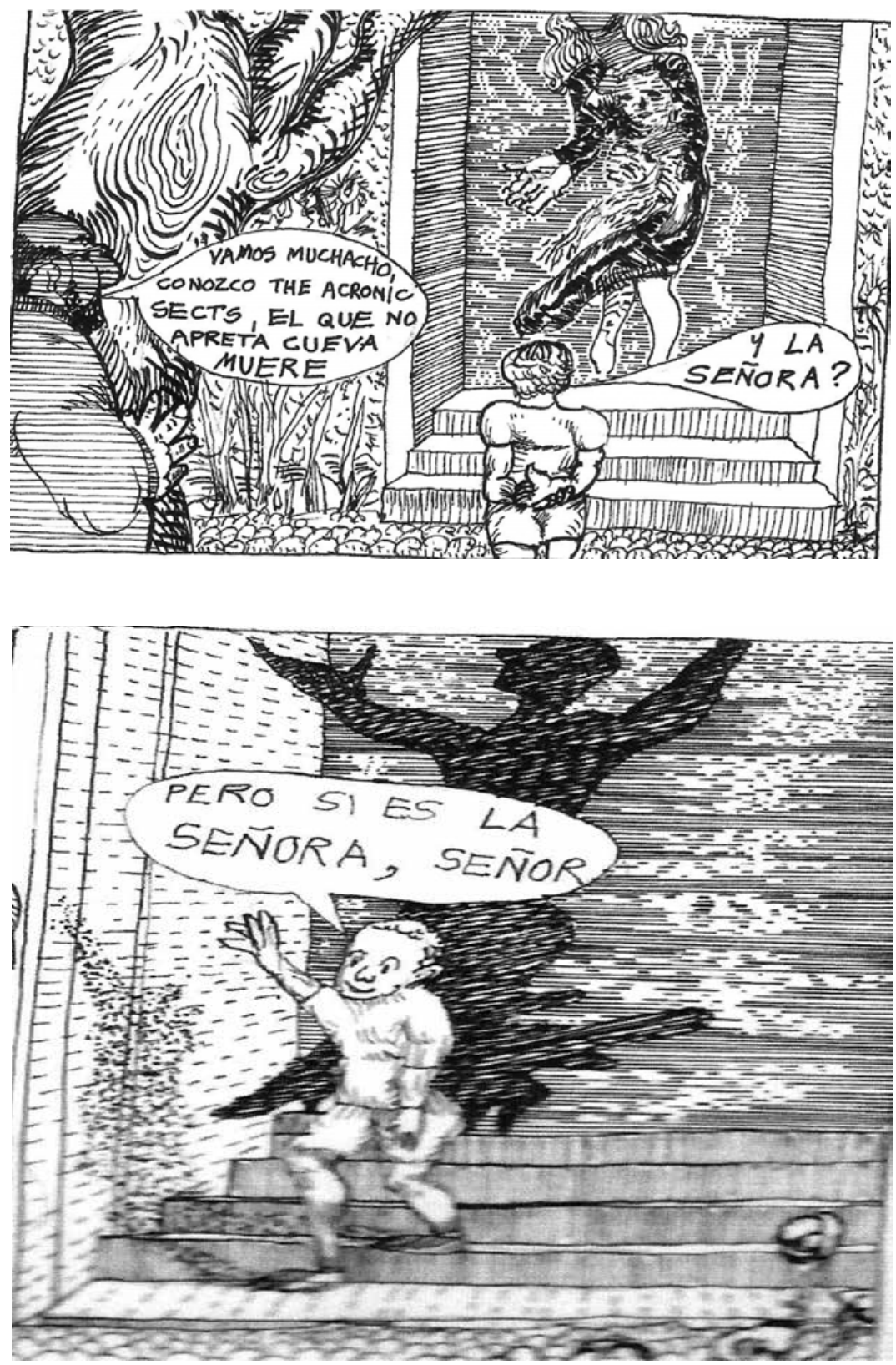


\section{Bibliografía}

Bisama, Alvaro. "El temblor en el trazo". Roma, la loba. Santiago: Ocholibros, 2011, 5-8.

Bolaño, Roberto. Los detectives salvajes. Barcelona: Anagrama, 2007.

Cánovas, Rodrigo, Roberto Merino, Lupe Santa Cruz, Miguel Vicuña Navarro. "Conversación inconclusa con Enrique Lihn (21 de junio de 1988)". Número quebrado 1 (septiembre-diciembre, 1988), 3-8.

Correa-Díaz, Luis. Lengua muerta-poesía, post-literatura $\mathcal{E}$ erotismo en Enrique Lihn. Providence, Rhode Island (USA): Ediciones INTI, 1996.

Debray, Régis. Vida y muerte de la imagen. Historia de la mirada en Occidente. Barcelona: Paidós, 1994.

.El arcaísmo posmoderno. Lo religioso en la aldea global. Buenos Aires: Manantial, 1996.

Gualandi, Alberto. Lyotard. Paris: Perrin, 2009.

Kristeva, Julia. Recherches pour une Sèmanalyse. Paris: Du Seuil, 1969. La révolution du langage poétique. Paris: Du Senil, 1974.

Lastra, Pedro y Adriana Valdés. "Nota preliminar". Diario de muerte. Santiago: Editorial Universitaria, 1989. P. 11-12.

Lihn, Enrique. Batman en Chile o El ocaso de un ídolo o solo contra el desierto rojo. Buenos Aires: Ediciones de la Flor, 1973. . El Paseo Ahumada. Santiago: Ediciones Minga, 1983.

- La aparición de la Virgen. Textos y dibujos de Enrique Lihn. Santiago: Cuadernos de Libre (E) Lección, 1987.

- Diario de muerte. Textos reunidos y transcritos por Pedro Lastra y Adriana Valdés. Santiago: Editorial Universitaria, 1989.

. Un Comic (Roma, la loba). Santiago: Pablo Brodsky Editor, 1992. . Roma, la loba. Santiago: Ocholibros, 2011.

. La aparición de la Virgen y otros poemas políticos (1963-1987). 
Santiago: Ediciones Universidad Diego Portales, 2012.

- Querido Pedro: Cartas de Enrique Lihn a Pedro Lastra (1967-1988).

Santiago: Das Capital Ediciones, 2012.

Lira, Rodrigo. Proyecto de Obras Completas. Santiago: Minga/Camaleón, 1984.

Lyotard, Jean-Francois. Discurso, Figura. Barcelona: Editorial Gustavo Gili, [1974] 1979.

. La condición posmoderna. Informe sobre el conocimiento. Madrid: Cátedra, [1979] 2004.

. La posmodernidad (explicada a los niños). Barcelona: Gedisa, [1986] 2008.

Martínez, Juan Luis. La nueva novela. Santiago: Ediciones Archivo, 1977.

Rodríguez, Mario. "Diario de muerte de Enrique Lihn: El deseo de la escritura." Acta Literaria 18 (1993): 25-53.

Sarmiento, Óscar. El otro Lihn. En torno a la práctica cultural de Enrique Lihn. New York: University Press of America, 2001.

Travis, Christopher M. Resisting Alienation - The Literary Work of Enrique Lihn. Lewisborg: Bucknell University Press, 2007.

Valdés, Adriana. Enrique Lihn: vistas parciales. Santiago: Editorial Palinodia, 2008.

Valdovinos, Mario. Lihn, La Muerte. Santiago: Traful Editores, 2012.

Zapata Gacitúa, Juan. "La aparición de la Virgen: poemas y dibujos de Enrique Lihn". El Sur [Concepción, Chile]. 3 de julio 1988: Suplemento, vii.

. "Enrique Lihn. Diario de muerte". Revista de crítica literaria latinoamericana 33 (1er. Semestre 1991): 326-327.

. Enrique Lihn: La imaginación en su escritura crítico-reflexiva. Santiago: Editorial La Nora, 1994. 